Cahiers $d u$ MONDE RUSSE

\section{Cahiers du monde russe}

Russie - Empire russe - Union soviétique et États indépendants

$46 / 4 \mid 2005$

L'invention d'une politique humanitaire

\title{
Vera A. Mil'čina, Rossija i Francija
}

\section{Catherine Depretto}

\section{OpenEdition \\ Journals}

Édition électronique

URL : https://journals.openedition.org/monderusse/6568

DOI : $10.4000 /$ monderusse. 6568

ISSN : $1777-5388$

Éditeur

Éditions de l'EHESS

Édition imprimée

Date de publication : 1 décembre 2005

Pagination : 867-868

ISBN : 2-7132-2057-2

ISSN : $1252-6576$

\section{Référence électronique}

Catherine Depretto, «Vera A. Mil'čina, Rossija i Francija », Cahiers du monde russe [En ligne], 46/4 I 2005, mis en ligne le 29 juin 2009, consulté le 03 septembre 2022. URL : http://

journals.openedition.org/monderusse/6568 ; DOI : https://doi.org/10.4000/monderusse.6568

Ce document a été généré automatiquement le 3 septembre 2022.

Tous droits réservés 


\title{
Vera A. Mil’čina, Rossija i Francija
}

\author{
Catherine Depretto
}

\section{RÉFÉRENCE}

Vera A. MIL'ČINA, Rossija i Francija : diplomaty, literatory, špiony [Russie et France : diplomates, hommes de lettres et espions] Saint-Pétersbourg: Giperion, 2004, 528 p.

(Filologičeskaja biblioteka, 4)

1 Il n'est sans doute pas besoin de présenter Vera Mil'čina, spécialiste reconnue des relations culturelles entre la Russie et la France dans la première moitié du xIX ${ }^{e}$ siècle et traductrice hors pair de Balzac, Chateaubriand, Constant, Nodier, et de Madame de Staël en particulier. Auteur de nombreux travaux savants et d'éditions commentées, dont $L a$ Russie en 1839 du marquis de Custine ${ }^{1}$, elle nous offre aujourd'hui un bon aperçu de ses sujets de prédilection comme de sa méthode avec le volume intitulé La Russie et la France: diplomates, hommes de lettres, espions qui rassemble dix-neuf articles, publiés pour la plupart entre 1995 et 2003 dans différents périodiques et ouvrages collectifs, retravaillés pour la présente édition, auxquels s'ajoutent quelques textes inédits.

2 Vera Mil'čina définit elle-même sa façon d'aborder l'histoire culturelle comme centrée sur le "quotidien idéologique», sur les faits en apparence mineurs ou marginaux, brochures oubliées, œuvres obscures, intrigues, rumeurs... Il ne faut pas voir là une accumulation empirique, un goût pour l'anecdotique en tant que tel, mais plutôt la volonté de reconstituer au plus près, de la façon la plus complète, la plus exacte, «le bruit du temps». Ce faisant, elle suit, en le revendiquant, l'exemple illustre de ses personnages favoris, tels que Petr Kozlovskij et surtout Aleksandr Turgenev qui, sous des allures de conteurs mondains, friands d'anecdotes, ont peut-être laissé sur leur époque les témoignages les plus pénétrants. Ses sujets tournent autour de l'actualité politique et littéraire de la Russie et de la France pour les années 1820-1840. Ils ont pour principaux acteurs des politiques, souverains, diplomates, comme des hommes de lettres, des figures de second plan (Durand, Marie-Melchior de Lagrené) et des personnages célèbres, Nicolas ${ }^{\text {er }}$ et Benkendorf, Puškin, Čaadaev, Petr Vjazemskij, le 
marquis de Custine... Ils parlent d'échanges culturels réels, mais aussi d'images mythiques, russes et françaises.

3 Alliant érudition et réflexion conceptuelle, le travail de Vera Mil'čina se situe à l'intersection de la recherche historique pure et des études littéraires. Il s'appuie sur une parfaite connaissance des sources publiées, sur le dépouillement systématique de la presse, périodiques français de la Restauration et de la monarchie de Juillet par exemple, et sur la publication de documents inédits, issus des archives diplomatiques, françaises et russes, du fonds de la III Section... Partout on retrouve une même maîtrise du matériau, un goût sûr du document, des traductions irréprochables et une capacité analytique sans faille, nourrie d'une intuition toute philologique. La démarche de Vera Mil'čina rappelle en plus d'une occasion la façon de procéder de l'historien Nathan Ejdel'man, sa « lecture lente ", qui lui permettait à partir d'un mot, d'une phrase, de retrouver le fil d'événements majeurs. C'est en ce sens que Vera Mil'čina peut être rangée parmi les représentants de la micro-histoire. Ce qui est le plus caractéristique dans son cas, ce n'est pas la volonté de travailler sur des objets circonscrits, mais plutôt son approche qui refuse les évidences, le cloisonnement des savoirs et la hiérarchisation des faits.

De ce point de vue, l'article « Pourquoi Puškin préférait-il Alphonse Karr à Balzac? » me semble un modèle du genre. Refusant de se satisfaire des commentaires rapides de ses prédécesseurs à propos d'une déclaration embarrassante du poète, Vera Mil'čina commence par « lire Karr », ce que personne n'avait vraiment fait auparavant, et propose ensuite une interprétation convaincante des raisons de l'intérêt de Puškin pour cet écrivain de second ordre comme de son apparente désaffection pour Balzac. L'examen d'épisodes en apparence anecdotiques, comme ce pari engagé entre Vjazemskij et Puškin à propos du sort attendant les ministres de Charles X, lui permet également d'ouvrir des perspectives insoupçonnées. Le réexamen critique de notations connues lui fait découvrir des éléments neufs, comme dans l'étude sur la présence de Čaadaev dans la prose française de son temps, ou dans son travail fondamental sur Barante et Puškin. Il y a là comme un micro-cycle pouchkinien, qui constitue un apport essentiel à l'étude d'un auteur pourtant déjà abondamment commenté.

5 Néanmoins, le cœur de l'ouvrage tourne autour de sujets plus directement historiques, concernant les relations diplomatiques entre la Russie et la France, ou encore l'épisode «custinien» que Vera Mil'čina maîtrise particulièrement bien (articles 9, 10, 11). Une part importante revient également à des thèmes moins connus, qui feront relativiser certaines idées toutes faites, comme le « mirage russe » des légitimistes français sous la monarchie de Juillet, l'image de la Russie dans la presse catholique et protestante, ou le " messianisme français».

6 Ces quelques éléments donneront, je l'espère, une idée adéquate de l'ampleur du travail de Vera Mil'čina, de la variété et de la richesse des sujets qu'elle traite comme de l'étendue de sa culture. Ses travaux, par leur érudition comme par leur souci de conceptualisation, contribuent largement au renouvellement des études comparatives sur le premier XIX ${ }^{e}$ siècle, une période un peu délaissée en France, en histoire comme en littérature, et qui était traitée à la période soviétique d'une façon unilatérale, en particulier en ce qui concerne la figure de Nicolas Ir ${ }^{\text {er }}$, présenté comme un souverain borné, ne connaissant que les vertus du knout. Malgré la fragmentation en articles, l'ouvrage donne une impression de cohérence qui tient à l'unité de la méthode et du style, mais aussi au retour des mêmes personnages d'un texte à l'autre, parfois dans des « emplois » différents. Ce trait qui n'est pas sans rappeler la Comédie humaine garantit 
une véritable restitution du " quotidien idéologique » de ce « milieu » bien spécifique auquel s'est consacré l'auteur. Et si entre la France et la Russie circulent un certain nombre d'idées fausses, il est aussi des esprits d'envergure, à l'aise en politique comme en littérature, également attachés aux deux pays et soucieux de contribuer à leur compréhension réciproque.

\section{NOTES}

1. Édition réalisée en collaboration avec A. Ospovat, deux volumes, M. : Sabašnikov, 1996 ; nouvelle édition revue: M.: Terra, 2000. Elle a aussi traduit et commenté (en coll. avec A. L. Ospovat), le Diorama social de Paris de Petr Kozlovskij, M., 1997. 